\title{
Educational Technology Research Past and Present: Balancing Rigor and Relevance to Impact School Learning
}

\author{
Steven M. Ross \\ Johns Hopkins University, United States \\ Gary R. Morrison \\ Old Dominion University, United States \\ Deborah L. Lowther \\ The University of Memphis, United States
}

\begin{abstract}
Today, the exponential growth of technology usage in education, via such applications of distance education, Internet access, simulations, and educational games, has raised substantially the focus and importance of educational technology research. In this paper, we examine the past and present research trends, with emphasis on the role and contribution of research evidence for informing instructional practices and policies to improve learning in schools. Specific topics addressed include: (a) varied conceptions of "effective" technology uses in classroom instruction as topics for research, (b) historical trends in research approaches and topics of inquiry; (c) alternative research designs for balancing internal (rigor) and external (relevance) validity; and (d) suggested directions for future research. Attention is devoted to describing varied experimental designs as options for achieving appropriate rigor and relevance of research evidence, and using mixed-methods research for investigating and understanding technology applications in complex real-life settings.
\end{abstract}

Keywords: Educational technology research; Technology and learning; Research designs and trends; Impact of technology on learning.

\section{Introduction}

Ever since the introduction of $16 \mathrm{~mm}$ film in the $1950 \mathrm{~s}$ and early drill-and-practice computer programs in the 1970s and 1980s, researchers have been interested in determining the effects of technology compared to traditional models of instruction (Morrison, Ross, Kemp, \& Kalman, 2010). Today, the exponential growth of technology usage in education, via such applications of distance education, Internet access, educational games, and simulations, has raised that focus immensely. For example, from 2004 to 2009, the number of yearly manuscript submissions to the Research section of Educational Technology Research and Development (ETR\&D), a top-ranked international journal, rose from 75 to 129 , an increase of $72 \%$. Recently, Robert Calfee (2006), as 
cited by Nolen (2009, p. 286), characterized educational technology in schooling to be one of the "Really Important Problems (RIP)" for future educational psychology researchers to examine.

On the other hand, concerns have been raised about the impact and quality of educational technology research. With regard to impact, Nolen (2009) recently concluded from an analysis of the content of 758 educational psychology studies published in leading journals that technology noticeably lagged behind other topics, such as classroom achievement, learning and memory, motivation, and cognition, as a focus of research in the broader educational psychology field. Specifically, she concluded:

Only $5.6 \%(n=43)$ of the articles in this study addressed issues around educational technology and learning. Another $2.5 \%(n=19)$ examined educational technology and the learning environment. Given the amount of technology available to students and to schools, it seems incumbent on educational psychologists to examine the impact of technology on schooling. (p. 286)

A second concern is a trend over the past two decades showing a decline in the quantity of experimental studies conducted on educational interventions, including those involving technology (Hsieh et al., 2005; Levin, 2004; Ross \& Morrison, 2008). This shift runs directly counter to the present emphasis on increased rigor in educational research for promoting usage of evidence-based practices (e.g., Eisenhart \& Towne, 2003; Slavin, 2008). Today, in 2010, many of the federal grant competitions in the U.S, specifically encourage or require rigorous experimentaltype designs for the evaluation component of funded projects. However, there is also growing interest in "design and development research" that examines the efficacy of computer-based tools and products for applications within specific contexts (Barab, 2006; Richey \& Klein, 2008). Methods commonly employed for such studies favor case studies, observations, expert reviews, and other qualitative and descriptive approaches.

The immense diversity of approaches to investigating technology applications in education precludes any straightforward evaluation or even characterization of the research field today. Equally strong rationales arguably can be made for the importance of research approaches ranging from (a) highly controlled basic-research studies of cognitive processes induced from interactions with computers (e.g., Kaufman, 2004; Lee, Lim, \& Grabowski, 2008); to (b) descriptive and exploratory studies of how learners use information and communication technologies as educational tools (Greenhow, Robelia, \& Hughes, 2009); to (c) contextually-specific "design-based research" studies of how particular technology products function in certain environments (Richey \& Klein; 2008; van den Akker \& Kuiper, 2008); to (d) applied research on solving specific problems that face major education providers in our society, such as schools and training organizations (see, e.g., Karr, Weck, Sunal, \& Cook, 2003; Ringstaff \& Kelly, 2002; Ross, Lowther, Wang, Strahl, \& McDonald, 2004). Accordingly, in attempting to achieve our goals for this paper-that of "evaluating" the past contributions of, and suggesting future directions for, educational technology research-a narrower focus than the "entire domain" of applications is required. Given our backgrounds as researchers of K-12 education, our selected purview is uses of technology to increase the effectiveness of teaching and learning in schools. Specific topics addressed in the sections below include: (a) varied conceptions of "effective" technology uses in schools as topics for research, (b) historical trends in research on educational technology; (c) 
alternative research designs for balancing internal (rigor) and external (relevance) validity; and (d) suggested directions for areas of inquiry and research approaches.

\section{Is Educational Technology Effective? Meaningful Domains for Research}

Is technology effective? That is the question continually asked by researchers, practitioners, and policy makers focusing on applications in schools. Most frequently, effectiveness is defined solely or primarily in terms of "effect sizes" indicating achievement gains for the treatment (technologysupported) condition over the control condition (e.g., Bernard et al., 2004; 2009; Dynarski et al., 2007; Russell, 1999). Concerns with this approach were perhaps most assertively voiced in the classic article by Richard Clark (1983) discouraging "media comparison" studies. Clark argued that it made little sense to compare different types of media-based instruction (e.g., lecture vs. computer-based instruction) to ascertain which one was "best." All types potentially could be effective or ineffective based on the quality of the instructional strategies employed. He viewed media as analogous to grocery trucks that carry food but do not in themselves provide nourishment (i.e., instruction). Alternative views are that educational technology provides unique "affordances" that make instructional events different than if conventional (e.g., teacher-led") delivery were used (Kozma, 1994). According to Morrison et al. (2010), such affordances also include making instruction more accessible to learners and easier to manage by teachers:

For example, we can use a distance education delivery strategy to reach additional members of our target audience and we can save time and money by making the instruction available at multiple locations rather than at one central location. Similarly, we could teach foreign vocabulary words to a learner with a drill-and-practice program that can manage the sequence and content of the material as well as providing immediate feedback. Unlike a teacher, the program can perform these tasks endlessly without tiring or becoming bored with the process (Chapter 10, p. X).

The perspective taken by researchers on the role of technology in classroom instruction influences the research questions pursued and the approach taken (e.g., qualitative vs. quantitative vs. mixed design) to answer them. As we have argued for several decades in agreeing with Clark, attempting to "prove" the effectiveness of technology through media comparison studies seems rather limiting and likely to under-represent potentially meaningful contributions to improving education (Morrison, 2001; Ross \& Morrison, 1989; Ross, Morrison \& Lowther, 2005). Educational technology is not a homogeneous "intervention" but a broad variety of modalities, tools, and strategies for learning. Its effectiveness, therefore, depends on how well it helps teachers and students achieve the desired instructional goals. Drawing on a recent paper (Ross \& Lowther, 2009), we describe three general domains as critical focuses for future studies.

\section{Technology as a Tutor}

The oldest and most-researched application of educational technology is computer-assisted instruction. Modern CAI programs provide tutorial lessons and drill-and-practice exercises adapted to students' needs. Graphics and animation make the materials more engaging and 
interesting than textbooks and workbooks. But is CAl likely to produce better learning than conventional, teacher-led instruction? Years of research suggest that both approaches generally produce similar results (Dynarski et al., 2007; Kulik, 2003; Slavin et al., in press). Although effective CAI programs use many evidence-based strategies (e.g., adaptive content, frequent testing, immediate feedback, etc.), so do effective teachers. Conversely, poorly designed CAI programs and boring, disorganized lecturers tend to produce low test scores and negative reactions from students. Rather than pitting computers against teachers, a more productive research approach is to investigate strategies for employing CAl efficaciously as a supplement to regular classroom instruction. Some valuable uses include (adapted from Ross \& Lowther, 2009):

- Giving students practice on core content and skills while freeing the teacher to tutor others, conduct assessments, or perform other tasks,

- Providing remedial instruction for low-achieving students,

- Providing enrichment activities for students who successfully complete the regular lesson before students who require more time to learn.

- Providing supplemental instruction when students do not have access to teachers (after school, during the summer, when absent from school),

- Teaching material in a different way to promote higher-order levels of learning or to assist those who failed to learn it the first time, and

- Preparing students for taking standardized tests by increasing familiarity with and fluency in answering representative questions.

\section{Technology as a Teaching Aid}

Another valuable role of technology is increasing teachers' effectiveness in organizing and presenting lessons. For example, the Reading Reels program, developed by the Success for All Foundation (Chambers, Cheung, Gifford, Madden, \& Slavin, 2006; Chambers et al., 2008) embeds strategically selected video segments and interactive question-and-answer exercises in daily lessons. Another example is establishing in distance education contexts "virtual classrooms" mediated by electronic technologies such as two-way audio and video (Keegan, 1977; Morrison et al., 2010; Simonson, Smaldino, Allbright, \& Zvacek, 2006).

Multimedia presentations extend teachers' abilities to make material more meaningful and engaging. But the more options teachers have for improving lesson quality, the greater the demands for organizing or "orchestrating" many diverse instructional activities. As an emerging technology innovation, interactive whiteboards have shown great promise in recent British studies for facilitating these organizational processes (Somekh, 2007). Because teachers and children can write on the whiteboard touch screen, learning becomes highly engaging and interactive. Organization of lessons is facilitated by teachers being able to preload lesson elements (e.g., PowerPoints, video, images, letters, words, etc.) and outlines directing lesson flow into the computer.

Yet another example of technology as a teaching aide is Interactive Classroom Communication Systems (commonly known as "clickers") (Penuel, Boscardin, Masyn, \& Crawford, 2007; Slavin, 2009). Using such devices, students can respond immediately to teacher questions, and answers 
are instantly aggregated and graphically displayed. Compared to conventional (non-technologyaided) instruction, advantages include (a) valuable immediate review and feedback for students, (b) immediate data on student progress for teachers to examine and use as a basis for making instructional adaptations, and (c) high engagement and interactivity by students during teacherled instruction.

\section{Technology as a Learning Tool}

While there is much research on how students learn from computers or about computers, there is a much greater need today to obtain scientific knowledge and data regarding student learning with computers. Disappointingly, after three decades of technology initiatives in the U.S., high levels of integration of technology with classroom learning remains much more the exception than the rule (Lowther, Inan, Strahl, \& Ross, 2009). A recent report from the U.S. Department of Commerce revealed that education is ranked as the least technology-intensive enterprise among 55 U.S. industry sectors (Lowther, Strahl, Inan, \& Ross, 2008). Just as sobering, a survey of over 400 U. S. employers revealed that high school graduates are entering today's workforce deficient in most of the $21^{\text {st }}$ Century knowledge and skills needed to achieve successful careers (CasnerLotto \& Barrington, 2006).

Viewed from these perspectives, proficiency in using technology for such contemporary tasks as searching the Internet, creating graphs and illustrations, and communicating through multimedia presentations has become an essential educational outcome, much like being proficient in reading and mathematics. Unfortunately, research shows that schools serving disadvantaged students are more likely than wealthier schools to use computers for CAI (drill-and-practice) functions than as a tool for meaningful learning. In discussing the potential of the Internet as a learning tool for literacy, Leu, O'Byrne, Zawlinski, McVerry, and Everett-Cacopardo (2009) cite research findings revealing that children in the poorest school districts have the least Internet access, while being under the greatest pressure to raise test scores having little to do with higher-level applications of technology. Wealthier students, however, are "doubly privileged by having Internet access at home, which in turn, makes it easier for their teachers to integrate Internet use into everyday classroom instruction. Thus, the socioeconomic gap is widening in this important domain.

In a series of recent quasi-experimental studies (Lowther et al., 2008; Lowther et al., 2009; Lowther, Ross. \& Morrison, 2003), we and our colleagues have examined efforts by multiple school districts to integrate computers as a learning tool. We describe some of this research later to encourage increased usage of mixed-methods designs for addressing real-world school issues. Briefly, what we found in the "computer-intensive" settings were increases in:

- student-centered, cooperative, and higher-order learning,

- student skills in writing, problem solving, and using technology,

- positive attitudes toward technology as a learning tool by students, parents, teachers, and school leaders,

- the quality and sustainability of technology integration programs when initial professional development was combined with ongoing in-school peer coaching. 
However, what we failed to find were achievement advantages for the technology-integration classes on state assessments. A straightforward, but non-analytical interpretation would be that the technology "treatment" was ineffective. But one major theme of the present paper is that it is incumbent on researchers to understand the multiple purposes and outcomes of complex technology interventions. In these cases, while the schools and the funders that sponsored the computer integration program would have been quite pleased for gains to occur on the state assessments, deeper reflection reveals that the major program activities were oriented to engender different types of short-term or "proximal" program outcomes-positive attitudes toward computers, improved technology skills, increased higher-order learning, etc. Achievement gains are highly important and probably essential to demonstrate for many intervention programs to survive in the long-run. As researchers, we therefore considered it necessary to analyze state assessment scores, while hypothesizing that such "distal effects" might not take place within the first few years of the technology integration program. If the program succeeded in engendering positive instructional and climate changes, then benefits for virtually all types of classroom learning would be expected to occur over time, including far transfer to standardized tests.

Given the essential goal of preparing today's students for higher education and careers, we encourage shifting emphasis from improving standardized test scores to a different research focus-how to use technology reflectively and scientifically to make teachers and curricula more effective. The above three forms of technology applications-- as a tutor, as a teaching aide, and as a learning tool--all show considerable promise for this purpose. The first two forms augment and enhance what teachers can do on their own to orchestrate and adapt instruction to individual needs. The latter form is directed to enabling students in all ethnic and socioeconomic groups to use technology effectively to master and perform $21^{\text {st }}$ Century skills. Positively influencing the future can only be enhanced by increased understanding of the past. We turn to this topic-a review of historical trends in technology research-in the next section.

\section{Research on Educational Technologies: Trends, Types, and Topics}

\section{Early Years: Technology as a Treatment}

An examination of trends in technology research was recently made by several authors in the third addition of the Handbook of Research on Educational Communications and Technology (Spector, Merrill, Merrienboer, \& Driscoll, 2008). As described by Hannafin and Young (2008), research on computer technology was initially (in the 1970s and 1980s) focused on the question, "Do computers improve learning?" The computer as compared to a teacher or a textbook, therefore, served as a "treatment" in research studies. Although the media comparison debate (Clark, 1983; Kozma, 1994) dampened some of the fervor in proving technology's viability as a causal treatment, we also are seeing a resurgence of interest (for better or worse) in this question today.

\section{Middle Years: Technology as a Delivery Mode}

During the late 1970's through the 1990's, the role of technology in research studies expanded from that of a treatment in itself to a means of conveying or delivering other treatment strategies 
(Hannafin \& Young, 2008). For example, computer-based instruction might be used to deliver and compare the effectiveness of different forms of feedback strategies (e.g., Morrison, Ross, Gopalakrishnan, \& Casey, 1995). Learner-control studies, which focused on the efficacy of individual learners selecting the quantity or type of instructional support presented in lessons, also became popular during that period (e.g., Hannafin \& Sullivan, 1996; Ross, Morrison, \& O'Dell, 1989). Again, computers served merely as a means of implementing the treatment (learner selected vs. prescribed instructional support) efficiently rather than as the research interest.

\section{Recent Years}

The ongoing media-effects debate (Clark, 1994; Clark \& Feldon, 2005; Kozma, 1994; Kozma, 2003) coupled with the continued popularity of constructivist theories of learning (Jonassen, 1994; Tobias \& Duffy, 2009) created new orientations for educational technology research through the 1990's and early 2000's. To capsule Hannafin and Young's analysis, the following emphases highlight this era (2008, pp. 733-734):

- Examining learning processes in open-ended learning environments (OLEs) and technology-enhanced learning environments (TELEs) in which students could apply technology to solve higher-order problems (e.g., manipulate variables and observe/evaluate effects in physics, chemistry, or mathematics etc.).

- Examining outcomes in "situated learning" contexts, such as the Jasper Woodbury series, developed to engage learners in simulations and higher-order processing involving authentic problems.

- Increasing emphases on "design-based research" (Richey \& Klein, 2008; van den Akker, \& Kuiper, 2008) to examine the effectiveness of TELEs and other computer-based instructional products within specific school contexts.

Most recently, we are seeing a proliferation of studies on cutting-edge technology applications such as distance learning (Bernard et al., 2004; 2009) and Web-based learning (Greenhow, Robelia, \& Hughes, 2009). Somewhat troubling is that the new research focuses tend to be disconnected from empirical findings obtained with older technologies (Hannafin \& Young, 2008) and from the broader educational field in general (Nolen, 2009). Recently, Kirby, Hoadley, and Carr-Chellman (2005) further discovered limited overlap with regard to citations and authorships between research conducted in the areas of educational technology and instructional systems. The Balkanization of these research streams weakens the efficiency and theoretical grounding of new research by designing interventions and associated studies as "blank slates" that ignore wellestablished principles of learning (e.g., cognitive load, verbal and visual memory, depth of processing, meaningful learning, etc.) and findings from basic educational psychology research (e.g., feedback studies, learner vs. program control, adjunct questioning, personalization, etc.). Credibility is further undermined through the failure to cite and draw from scholarship that is influential and widely cited in the literature.

Earlier in this paper, we noted the current movement in the U.S. supporting increases in research rigor to identify "what works" (Eisenhart \& Towne, 2003; Slavin, 2008). The federally-funded What Works Clearinghouse (http://ies.ed.gov/ncee/wwc/) regularly releases reports on the effects 
of programs that have "sufficient" research evidence from quasi- and randomized-experimental studies meeting high standards of rigor. For educational technology research, the fervor of identifying "what works" carries the associated long-standing risk (Clark, 1983) of confusing delivery modes with instructional strategies.

For example, in a recent large-scale randomized field trial funded by the Institute of Educational Sciences (IES), Dynarski et al, (2007) investigated the effectiveness of computer-based instruction (CAI) tutorials in reading and mathematics. A total of 158 teachers from 43 schools in 11 districts and their 2,619 students were randomly assigned within schools to CAI or control conditions. CAI students used the programs for an average of 94 minutes per week. Control classes also often had computers, and used them for an average of 18 minutes per week on activities such as reading assessments and practice. Initial and follow-up studies showed equivocal results and fairly small effect sizes for the technology group on standardized achievement tests (SAT-9) in the respective subjects. A seemingly unfortunate interpretation of these results was that technology was "ineffective" (Trotter, 2007). More reflective consideration of the study design, however, suggest a number of reasonable explanations for why a technology intervention of limited intensity (averaging less than 20 minutes per day for only half the school year), adopted by teachers in an artificial context (random selection as part of an experiment) might fail to produce meaningful effects on a standardized test. One could just as easily argue, as the news media failed to do (as in Trotter, 2007), that the CAI was successful as a result of producing slightly higher outcomes than conventional instruction, while freeing the teacher to perform other important tasks (e.g. tutoring individual students, reviewing assessment data, planning lessons, etc.).

For educational technology research to help solve real-world educational problems, we advocate that studies increasingly reflect two qualities. One is to achieve balance between rigor (internal validity) and relevance (external validity). The second is to focus on meaningful application topics that deal directly with teaching and learning challenges and practices in today's classrooms. We deal with these topics next.

\section{Balancing Internal and External Validity: Alternative Research Designs}

What research approaches need to be emphasized in the field today? How can researchers make the best choices in planning and conducting a study? There is no simple answer. Philosophical and epistemological views about learning and cognition enter strongly into the equation, as do considerations about needs for high rigor and control, audience interests, practicality, time constraints, and resources. We believe, as argued above, that a useful starting point is evaluating potential design options to ensure an adequate balance between internal validity--the degree to which one can draw valid conclusions about the causal effects of one variable on another, and external validity--the degree to which results can be generalized to conditions of interest. Regarding this theme, it is noteworthy that, John Q. Easton, the new head of the U.S. Department of Education's key research agency (the Institute of Educational Sciences, recently advocated new directions for federally-funded educational research in 2010 and beyond (Viadero, 2009). While he views promoting rigorous research through randomized experiments as still an important part of the agenda, increased attention to "relevance" and "usefulness" of research is also considered necessary for gaining understanding of why particular findings were obtained. 


\section{Experimental Designs}

Over the last one-hundred years, experimental research has been widely revered and extensively used in education (Hannafin \& Young, 2008; Ross \& Morrison, 2008; Ross et al., 2005). Today, in the view of many policy makers and research consumers, randomized experiments comprise the "gold standard" of research approaches (Slavin, 2008). But a highly rigorous experimental study that produces evidence from unrealistic or artificial conditions can well be "fool's gold" for informing educational practices. As an example, consider an experimental study that demonstrates improved student learning of chemistry principles when computer-based lessons provide answer-sensitive feedback. Assuming high internal validity, we can confidently attribute the learning benefits as "caused" by the feedback strategy rather than other variables, such as higher-ability students, increased time to learn, or easier tests. If, however, the students received an unusually high degree of assistance from the researchers in using the CBI program, the results would have limited generalizability (low external validity) to the very school applications that the strategy is designed to support.

\section{True experiments}

To maximize internal validity, the most powerful design is the true experiment (Slavin, 2008). Its distinguishing feature is the random assignment of participants (e.g., learners, classrooms, schools) to treatments, thereby eliminating any systematic error that could occur if treatment and control groups had differing potential to perform well. An example would be assigning half of college student volunteers to a condition where metacognitive prompting (e.g., "Think about which answers would be best given what you learned") is provided on a computer-based lesson and half to a condition where no prompting is provided.

Although the true (often called "randomized") experiment is potentially high in rigor, it can easily be susceptible to low external validity. The above example (chemistry application) is illustrative of the type of study reported in large portion of manuscripts submitted to ETR\&D (including quite a few of our own earlier papers), whereby student volunteers agree, often for an incentive of some type (e.g., extra credit), to try to learn instructional material to which they normally would not be exposed. Although learning conditions can be highly controlled in such settings, the results may not reflect sufficiently the implementation challenges that regular teachers might experience or the learning activities and motivation of actual students being held accountable for required course material. As described earlier, the national randomized study of CAl tutorials (Dynarski et al., 2007) randomly selected teachers to use instructional software in reading or mathematics instruction or to teach in the usual manner. Despite the advantages of randomization, the condition of being "assigned" for research purposes to use or not use an intervention is certainly atypical of how teachers and their schools normally adopt technology applications (see, e.g., Ertmer, 2005; Ertmer, Gopalakrishman, \& Ross, 2001). 


\section{Quasi-experiments}

In actual school settings, it is frequently impractical to randomly assign participants to treatments. Where teachers are the unit of assignment, individuals within a school may resent that they were not (or were) chosen to employ the experimental strategy. School principals, too, may view it disruptive to have alternative programs being implemented simultaneously in the same grades. The label "quasi-experiment" is used today (sometimes incorrectly in a technical sense) to refer to a family of designs that share the characteristic of assigning preexisting or self-selected groups to the experimental and control conditions. Internal validity and rigor for inferring causality are determined largely by the equivalence of groups. Briefly, varied quasi-designs include:

- Randomized quasi experiment: This relatively new classification refers to designs in which schools or classes are randomly assigned to experimental and control treatments, but there are too few to justify analysis at the level of random assignment (e.g., 3 schools are assigned to use a new technology-supported program and 3 to use existing approaches). The random assignment increases the chances of establishing equivalent groups over a matched design (see below), but to a lesser degree than with a sufficiently large sample (e.g., 20 schools or classes in each condition).

- Matched quasi-experiment: In this frequently used design, the experimental group is selfselected based on participants' decision to implement the treatment of interest. For example, had the CAl software study (Dynarski et al., 2007) employed a matched as opposed to randomized design, schools might have been assigned to the treatment group based on their interest in implementing the software programs. Control schools would have then been selected on the basis of being highly similar to the volunteer schools on key variables (e.g., prior test scores, student characteristics, school size, teacher experience, etc.). Relative to a randomized design, internal validity is threatened by the possibility of the volunteer schools having superior teachers, better principals, or more positive climates. External validity, however, may be enhanced by reproducing the real-world condition where schools adopt an intervention based on readiness and interest rather than random selection in an experiment. Even more authentic (but concomitantly more subject to sampling biases) is populating the treatment group with schools that have chosen the intervention independently of the experiment.

- Causal comparative: This approach has characteristics of both quasi-experiments and correlational (see below) studies. Pre-existing groups are employed as the treatment and control samples, but the groups are established by defined, intrinsic characteristics of the participants, such as ethnicity, educational background, socioeconomic status, etc. For example, Jeung \& Davidson-Shivers (2006) compared males and females who participated in computer-supported online debates. Here, the treatment groups were defined by student characteristics (i.e., gender) rather than by self-selection (e.g., matched design) or experimenter assignment (random design). Although "groups" were compared, the design is correlational in nature, asking the question of whether gender relates to response patterns in computer-supported argumentation. Interest, therefore, is directed to investigating the benefits of technology for different types of users rather than compared to alternative treatments. An enhanced design might randomly assign half of the males and half of the females to alternative technology-supported conditions, thereby creating a combined causal comparative and randomized experimental design. 
- Regression continuity. In this type of quasi-experiment, participants are assigned to a treatment or control group based on a cut-off score or other quantitative index. For example, suppose that a federal program offers a new computer-based reading curriculum only to schools that scored below the $25^{\text {th }}$ percentile on the state reading assessment. To evaluate the program, the researchers decide to select as control schools those that scored just above the cut-off $\left(26^{\text {th }}\right.$ $30^{\text {th }}$ percentile), the closest match possible for increasing internal validity. External validity should be reasonably high, since only those who were eligible for the program receive it under normal conditions.

- Interrupted time series. In this quasi-experimental design, the outcome of interest (e.g., skills in navigating Web 2.0) is measured multiple times before and after the treatment (e.g., a peer-assisted training module) for the experimental group only. If the treatment had an impact, the performance pattern should be upward on the post-treatment trials. Adding an equivalent control group would combine this approach with the matched design, thereby increasing internal validity.

- Correlational: These non-experimental designs are convenient to employ and usually high in external validity due to measuring relationships between variables under natural conditions (e.g., investigating whether students having home computers demonstrate better keyboarding skills than those without home computers). But the disadvantage is the possibility of uncontrolled intervening variables influencing the results (e.g., the students having home computers also received formal instruction in keyboarding from their parents, software, computer camps, etc.).

\section{Mixed Methods Designs}

The complexities of applying technology to education, particularly in realistic K-12 settings, suggest the need for research evidence that is more than simply quantitative indicators of "effects" on isolated outcome measures. On the other hand, practitioners are of necessity vitally interested in such outcome data for deciding which technology-based products to adopt. Receiving researchers' subjective (i.e., "qualitative") impressions as the only evidence would not be sufficient. "Mixed methods" research describes studies that combine both quantitative methodsto yield data on effects or impacts-and qualitative methods-to yield data on the implementation processes and other contextual factors potentially influencing those impacts (Johnson, \& Onwuegbuzie, 2004; Richey \& Klein, 2008). For illustrative purposes, we describe below our use of mixed methods designs in evaluation studies that were both rigorous and impactful in applied $\mathrm{K}-12$ contexts.

Our evaluation of the Tennessee EdTech Launch (TnETL) initiative provides an excellent example of using mixed-methods approaches in both a quasi-experiment and random control trial to achieve the rigorous research required by federal funders, yet yield relevant outcomes for K-12 educators (Lowther, Ross, Wang, Strahl, \& McDonald, 2004). The three-year statewide TnETL program used a two-cohort design that collectively involved 54 schools ( 27 treatment; 27 control), 28,735 students and 1,746 teachers (Lowther et al., 2008). The technology integration approach of TnETL was to provide full-time, on-site technology coaches to prepare teachers to create lessons that engage students in critical thinking and use of computers as tools in order to increase learning. 
The qualitative and quantitative data collected for cohort 1 (quasi-experimental) and cohort 2 (random control) consisted of classroom observations, teacher and technology coach surveys, student problem-solving and technology performance assessments, principal and technology coach interviews, teacher focus groups, school-developed technology benchmarks, and student achievement analysis for mathematics and reading/language arts. If only quantitative data were collected for TnETL, efforts of the three-year initiative may have been dismissed as student-level achievement results on state assessments were mixed. However, by using a mixed methods approach the resulting comprehensive data set not only supported rigorous analyses of student achievement, but also provided a wide array of contextual information to examine the emergence of technology integration patterns and trends. Of key importance, these findings supported the course of actions for future Tennessee technology initiatives.

For example, observation data revealed that program students more frequently used computers as tools and for instructional delivery, and were more frequently engaged in project-based learning, cooperative groups, and student-conducted research. Yet, the frequency with which the practices were observed was moderately low, which prompted the state technology director to increase teacher professional development and extend contracts for technology coaches in subsequent years. Survey results showed that program teachers had significantly higher confidence to integrate technology and use technology for learning, yet revealed teacher concerns about spending classroom instruction time to fix computer problems. TnETL addressed this concern by funding part-time computer technicians. Further, the technology coach interviews revealed that computers were not in place at the start of year 1 due to late distribution of funds. This information resulted in a change in the funding schedule to guarantee that computer purchases and set-up would be complete before school begins. The key point of emphasis is that the mixed methods approach provided rigorous and relevant quantitative and qualitative results needed by TnETL to guide the direction of future technology integration initiatives.

\section{What is Being Published: An Informal "Gap Analysis"}

To increase understanding about current trends in educational technology research and possible "gaps" to be addressed in future work, it should be informative to examine the types of studies being published in journals. Because conducting an exhaustive analysis is beyond the scope of this paper, we adopted the more modest goal of providing general impressions based on a three-year examination (2006-2008) of a leading international journal-Educational Technology Research and Development. Published articles that used a systematic collection of data were included in this analysis. A total of 43 articles published between 2006 and 2008 in the Research and Development sections of the journal were selected and analyzed.

The articles were first classified by the research design (true experiment, quasi experimental, correlational-causal, descriptive, summary/synthesis, or mixed) employed and then by the type(s) of data collected (quantitative only, qualitative only, or mixed methods). The summary/synthesis category included articles that analyzed data from other studies using a variety methods including meta analysis. We did not include any of the published literature reviews as they did not manipulate data from prior studies. 


\section{Research Designs Employed by Studies}

The majority of the articles (25) were classified as using a descriptive design. These studies utilized case studies, design-based studies, developmental research, formative evaluation, observation, surveys, and qualitative studies. The number and percentage of articles employing each design is summarized in Table 1.

Table 1. Research Designs Used in Studies

\begin{tabular}{lll}
\hline Methodology & Frequency & Percentage \\
\hline True Experiment & 8 & $19 \%$ \\
Quasi Experimental & 7 & $16 \%$ \\
Correlational-causal & 1 & $2 \%$ \\
Descriptive & 25 & $58 \%$ \\
Summary/Synthesis & 2 & $5 \%$ \\
\hline
\end{tabular}

In a previous study (Ross \& Morrison, 2004), we found a different trend in the use of research designs for articles published in the same journal from 1953 to 2001. During this time period, trueexperimental designs were used in $58 \%$ of the articles and descriptive studies only accounted for $19 \%$ of the studies published. One-fifth (20\%) of the studies employed quasi-experimental designs and the remaining 3\% used a time series design. In the last three years, there has been a shift from true and quasi-experimental designs, which formerly accounted for $78 \%$ of the research designs, to only $35 \%$. In the same comparison, we have seen increased use of descriptive research designs from $19 \%$ to $58 \%$ in the journal.

\section{Types of Data Collected}

The second analysis of the selected articles was used to determine the type of data collected. Articles were classified as using quantitative only, qualitative only, or mixed methods. Qualitativeonly data approaches were used in $44 \%$ of the published studies. Table 2 provides a summary of the data collection types, and Table 3 a summary of research designs by data collection types. The latter data show a mixed method approach to be more common in true and quasi-experimental designs. A qualitative-only approach is most likely to be used in descriptive studies, which is expected given the nature of the qualitative research methods (i.e., case studies and observational studies). 
Table 2. Types of Data Collected

\begin{tabular}{lcc}
\hline Data Type & Frequency & Percentage \\
\hline Quantitative only & 10 & $23 \%$ \\
Qualitative only & 19 & $44 \%$ \\
Mixed data & 14 & $33 \%$ \\
\hline
\end{tabular}

Table 3. Research Design x Data Collection

\begin{tabular}{|c|c|c|c|}
\hline \multirow[t]{2}{*}{ Research Design } & Quantitative only & Qualitative Only & Mixed \\
\hline & Frequency (\%) & Frequency (\%) & Frequency \\
\hline True experiment & 1 (13) & (0) & 7 (88) \\
\hline Correlational-Causal & 1 (100) & (0) & $0 \quad(0)$ \\
\hline Descriptive & $4 \quad(16)$ & (72) & $3(12)$ \\
\hline Summary/Synthesis & $2(100)$ & (0) & $0 \quad(0)$ \\
\hline Quasi-experiment & 2 (29) & (14) & 4 (57) \\
\hline
\end{tabular}

In previous analyses of the literature, Hsieh et al. (2005) and Ross and Morrison (2008) voiced a concern regarding the lack of intervention studies in the educational psychology and instructional technology literature. Both studies found a drop in the number of intervention studies during the 1995-2004 timeframe when compared to 1983 which was used as a baseline. While the current analysis did not classify articles as intervention studies or non-intervention studies, we can draw a general conclusion based on the research designs employed in the studies. Intervention studies require an experimental design such as a true or quasi-experiment. Only $35 \%$ of the studies in the present review employed these two types of designs, suggesting that only about one-third or fewer of the publications were intervention studies. This finding contrasts with our earlier finding that $75 \%$ of the studies published in 1983 were intervention studies. The current estimated trend is also less than the 45\%, of intervention studies published between 1995 and 2004. This declining trend of experiments and intervention studies raises some concerns about the rigor of technology studies for identifying effective practices in schools.

\section{Directions for the Future}

As the preceding sections convey, characterizing, let alone evaluating, educational technology research over the past few decades is a daunting task. This enormous body of research addresses countless diverse topics and incorporates the entire gamut of designs, ranging from qualitativedescriptive to randomized experiments. In being asked for this paper to propose directions for improving the relevance (meaningfulness and utility) and quality (rigor and credibility) of research, we accept that many alternative viewpoints, each having its own compelling rationale, are likely to exist. We therefore proceed with the caveat that our ideas reflect our personal biases based on 
our experiences in conducting research and helping practitioners to use technology more effectively in the field.

One premise for our recommendations is that relevant and quality research addresses problems and issues of contemporary importance in education. This idea accepts the need for continued basic research on cognition and learning using technology (e.g., Azevedo \& Cromley, 2004; Azevedo, Cuthrie, \& Seibert, 2004) as well as formative evaluation and design-based research (Morrison et al., 2010; Richey \& Klein, 2008; van den Akker, \& Kuiper, 2008) to develop and refine technology products. They do, however, place priority on well-designed studies that directly help practitioners to improve teaching and learning in applied contexts. A second premise is that relevant and quality research must be rigorous so that their results are viewed as reliable and valid. A third premise is that relevant and quality research must do more than simply present evidence about how well a technology application worked. Just as important as knowing the overall findings is being able to interpret why they occurred with regard to such factors as attributes of the particular setting (e.g., rural vs. urban school), fidelity of the implementation (fully implemented vs. applied weakly or partially), and reactions of participants (highly motivation vs. disinterested in the task). In taking these views, we are pleased to hear that the same emphases are now being espoused in the U.S. by the new head of the Institute of Educational Sciences, arguably the most influential research agency in our country (Viadaro, 2009).

Research design, obviously, has limited value in informing K-12 practices in the absence of meaningful areas of inquiry. What topics appear important today and potentially in the next decade for improving education via technology? In our opinion, we suggest the following four for consideration:

- Distance learning, including Web-based courses, teleconferencing, blended (hybrid) courses, etc.

- Social networking with a global community of learners

- Integrating technology as a learning tool in classroom instruction

- Teaching students to become skilled and confident users of technology

As technology continues to rapidly gain increased usage and importance in K-12 education, the next decade will undoubtedly offer unprecedented opportunities for research findings to inform practices for enhancing teaching and learning. To achieve that goal, we encourage researchers to reduce efforts to prove the "effectiveness" of technology, while focusing on conducting rigorous and relevant mixed-methods studies to explicate which technology applications work to facilitate learning, in what ways, in which contexts, for whom, and why.

\section{References}

Azevedo, R., \& Cromley, J. G. (2004). Does training of self-regulated learning facilitate students' learning with hypermedia? Journal of Educational Psychology, 96, 523-535.

Azevedo, R., Cuthrie, J. T., \& Seibert, D. (2004). The role of self-regulated learning in fostering students' conceptual understanding of complex systems with hypermedia. Journal of Educational Computing Research, 28(1), 15-30. 
Barab, S. (2006). Design-based research: A methodological toolkit for the learning scientist. In R. K. Sawyer (Ed.), Cambridge handbook for the learning sciences (pp. 153-170). Cambridge, UK: Cambridge University Press.

Bernard, R. M., Abrami, P. C., Borokhovski, C., Wade, C. A., Tamin, R. M., Surkes, M. A., \& Bethel, E. C. (2009). A meta-analysis of three types of interaction treatments in distance education. Review of Educational Research, 79(3), 1243-1289.

Bernard, R. M., Abrami, P. C., Lou, Y., Borokhovski, E., Wade, C. A., Wozney, L., Wallet,P. W., Fiset, M., \& Huang, B. (2004). How does distance education compare with classroom instruction? A meta-analysis of the empirical literature. Review of Educational Research, 74, 379-439.

Calfee, R. (2006). Educational psychology in the $21^{\text {st }}$ century. In P. A. Alexander \& P. H. Winne (Eds.) Handbook of educational psychology ( $2^{\text {nd }}$ Ed., pp. 29-42). Mahwah, NJ: Erlbaum.

Casner-Lotto, J. \& Barrington, L. (2006). Are they really ready to work: Employers perspectives on the knowledge and applied skills of new entrants to the 21st Century U.S. workforce. The Conference Board, Inc., the Partnership for 21st Century Skills, Corporate Voices for Working Families, and the Society for Human Resource Management. Retrieved January 21, 2008 from http://www.21stcenturyskills.org/index.php?option=com_content\&task=view\&id=82\&lte $\operatorname{mid}=40$.

Chambers, B., Cheung, A., Gifford, R., Madden, N., \& Slavin, R. E. (2006). Achievement effects of embedded multimedia in a Success for All reading program. Journal of Educational Psychology, 98, 232-237.

Chambers, B., Slavin, R. E., Madden, N. A., Abrami, P. C., Tucker, B., J., Cheung, A., \& Gifford, R. (2008). Technology infusion in Success for All: Reading outcomes for first graders. Elementary School Journal, 109 (1), 1-15.

Clark, R. E. (1983). Reconsidering the research on learning from media. Review of Educational Research, 53(4), 445-459.

Clark, R. E. (1994). Media will never influence learning. Educational Technology Research and Development,42, 21-29.

Clark, R. E. \& Feldon, D. F. (2005). Five common but questionable principles of multimedia learning. In R. E. Mayer (Ed.) The Cambridge Handbook of Multimedia Learning (pp. 97115). New York: Cambridge University Press.

Dynarski, M., Agodini, R., Heaviside, S., Novak, T., Carey, N., Campuzano, L., Means, B., Murphy, R., Penuel, W., Javitz, H., Emery, D., \& Sussex, W. (2007). Effectiveness of reading and mathematics software products: Findings from the first student cohort. Washington, DC: Institute of Education Sciences.

Eisenhart, M., \& Towne, L. (2003). Contestation and change in national policy on "scientifically based" education research. Educational Researcher, 32(7), 31-38.

Ertmer, P. A. (2005). Teacher pedagogical beliefs: The final frontier in our quest for technology integration? Educational Technology Research and Development, 53(4), 25-39. 
Ertmer, P. A., Gopalakrishnan, S., \& Ross, E. M. (2001). Technology-using teachers: Comparing perceptions of exemplary technology use to best practice. Journal of Research on Technology in Education, 33(5). Retrieved January 4, 2008 from http://www.iste.org/jrte/33/5/ertmer.html.

Greenhow, C., Robelia, B., \& Hughes, J. E. (2009). Web 2.0 and classroom research: What path should we take now? Educational Researcher, 38(4), 246-259.

Hannafin, R. D., \& Sullivan, H. J. (1996). Learner preferences and learner control over amount of instruction. Journal of Educational Psychology, 88, 162-173.

Hannafin, R. D., \& Young, M. (2008). Research on educational technologies. In M. Spector, M. D. Merrill, J. V. Merrienboer, \& M. Driscoll (Eds.). Handbook of research on educational communications and technology, Third Edition (pp. 731-739). New York: Routledge.

Hsieh, P., Acee, T., Chung, W., Hsieh, Y., Kim, H., Thomas, G., Levin, J. R., \& Robinson, D. H. (2005). Is educational intervention research on the decline? Journal of Educational Psychology, 97(4), 523-529.

Jeong, A., \& Davidson-Shivers, G.V. (2006).The effects of gender interaction patterns on participation in computer-supported collaborative argumentation. Educational Technology Research and Development, 54(6), 543-568.

Johnson, R. B., \& Onwuegbuzie, A. J. (2004). Mixed methods research: A research paradigm whose time has come. Educational Researcher, 33(7), 14-26.

Jonassen, D. H. (1994). Thinking technology: Toward a constructivist design model. Educational Technology 34(4), 34-37.

Karr, C. L., Weck, B., Sunal, D. W., \& Cook, T. M. (2003). Analysis of the effectiveness of online learning in a graduate engineering math course. Journal of Online Interactive Learning, 1(3)., from www.ncolr.org/jiol/achieves/2003/winter/3/ms02023_Karr.

Kauffman, D. F. (2004). Self-regulated learning in web-based environments: Instructional tools designed to facilitate cognitive strategy use, metacognitive processing, and motivational beliefs. Journal of Educational Computing Research, 30, 139-161.

Keegan, D. (1996). Foundations of distance education (3rd ed.). London: Routledge.

Kirby, J. A., Hoadley, C. M., \& Carr-Chellman, A. A. (2005). Instructional systems design and the learning sciences: A citation analysis. Educational Technology Research \& Development, 53, 37-48.

Kozma, R. B. (1994). Will media influence learning? Reframing the debate. Educational Technology Research and Development, 42, 7-19.

Kozma, R. B. (2003). Technology and classroom practices: An international study. Journal of Research on Technology in Education, 36(1), 1-14.

Kulik, J. A. (2003). Effects of using instructional technology in elementary and secondary schools: What controlled evaluation studies say. SRI Project Number P10446.001. Arlington, VA: SRI International. 
Lee, H. W., Lim, K. Y., \& Grabowski, B. L. (2008). Generative learning: Principles and implications for making meaning. In M. J. Spector, D. M. Merrill, J. van Merrienboer \& M. P. Driscoll (Eds.), Handbook of research and educational communications and technology (3rd ed.). New York, NY: Taylor \& Francis Group.

Leu, D. J., O’Byrne, W. I., Zawlinski, L., McVerry, G., \& Everett-Cacopardo, H. (2009). Expanding the new literacies conversation. Educational Researcher, 38(4), 264-269.

Levin, J. R. (2004). Random thoughts on the (in)credibility of educational-psychological intervention research. Educational Psychologist, 39(3), 173-174.

Lowther, D.L., Inan, F.A., Strahl, J.D., Ross, S.M. (2008). Does technology integration "work" when key barriers are removed? Educational Media International, 45(3), 195-206.

Lowther, D. L., Inan, F. A., Strahl, D. J., \& Ross, S. M., (April, 2009). Do one-to-one initiatives bridge the way to $21^{\text {st }}$ Century Knowledge and Skills? Paper presented at the 2009 American Educational Research Association National Conference, San Diego, CA.

Lowther, D. L., Ross, S. M., \& Morrison, G. R. (2003). When each one has one: The influences on teaching strategies and student achievement of using laptops in the classroom. Educational Technology Research and Development, 51(03), 23-44.

Lowther, D. L., Ross, S. M., Wang, L. W., Strahl, D., \& McDonald, A. (2004). Tennessee Department of Educational EdTech Launch 1 2003-2004 Evaluation Report. Memphis, TN: The University of Memphis, Center for Research in Educational Policy.

Morrison, G. R. (2001). Equivalent evaluation of instructional media: The next round of media comparison studies. In R. E. Clark (Ed.), Learning from instructional media: Arguments, analysis, and evidence (pp. 319-326). Greenwich, CT: Information Age Publishers.

Morrison, G. R., Ross, S. M., Gopalakrishnan, M., \& Casey, J. (1995). The effects of feedback and incentives on achievement in computer-based instruction. Contemporary Educational Psychology, 20, 32-50.

Morrison, G. R., Ross, S. M., Kemp, J. E., \& Kalman, H.(2010). Designing effective instruction: Applications of instructional design (6th. Ed.), New York, NY: Wiley.

Nolen, A. L. (2009). The content of educational psychology: An analysis of top-ranked journals from 2003 to 2007. Educational Psychology Review, 21, 279-289.

Penuel, W. R., Boscardin, C. K., Masyn, K., \& Crawford, V. M. (2007). Teaching with student response systems in elementary and secondary education settings: A survey study. Educational Technology, Research \& Development, 55 315-346.

Richey, R. C., \& Klein, J. D. (2008). Research on design and development. In M. Spector, M. D. Merrill, J. V. Merrienboer, \& M. Driscoll (Eds.). Handbook of research on educational communications and technology, Third Edition (pp. 748-757). New York: Routledge.

Ringstaff, C., \& Kelly, L. (2002). The learning return on our educational technology investment: A review of findings from research. San Francisco, CA: WestEd RTEC.

Ross, S.M. \& Lowther, D.L. (2009). Effectively using technology in education. Better Evidence-Based Education, 2(1), 20-21. 
Ross, S. M., Lowther, D. L., Wang, L. W., Strahl, J. D. \& McDonald, A. J. (2004). Tennessee Department of Education EdTech Launch 1 2003-2004 Evaluation Report. Memphis, TN: The University of Memphis, Center for Research in Educational Policy.

Ross, S. M., \& Morrison, G. R. (1989). In search of a happy medium in instructional technology research: issues concerning internal validity, media replications, and learner control. Educational Technology Research and Development, 37, 19-24.

Ross, S. M. \& Morrison. G. R. (2004). Experimental research methods, In D. J. Jonassen (Ed). Handbook of research on educational communications and technology, $2^{\text {nd }}$ Ed., (pp. 10211043). Mahwah, NJ: Lawrence Erlbaum Associates, Publishers.

Ross, S. M., \& Morrison, G. R. (2008). Research on instructional strategies. In M. Spector, M. D. Merrill, J. V. Merrienboer, \& M. Driscoll (Eds.). Handbook of research on educational communications and technology, Third Edition (pp. 719-730). New York: Routledge.

Ross, S. M., Morrison, G. R., \& Lowther, D. L. (2005). Using experimental methods in higher education. Journal of Computing in Higher Education, 16(2), 39-64.

Ross, S. M., Morrison, G. R., \& O'Dell, J. K. (1989). Uses and effects of learner control of context and instructional support in computer-based instruction. Educational Technology, Research, and Development. 37, 29-39.

Russell, T. L. (1999). The no significant difference phenomenon. Chapel Hill: Office of Instructional Telecommunications, North Carolina State University.

Slavin, R. (2008). What works? Issues in synthesizing education program evaluations. Educational Researcher, 37 (1), 5-14.

Slavin, R. E. (2009). Educational Psychology: Theory into Practice (Ninth Edition). Upper Saddle River, NJ: Pearson.

Slavin, R.E., Lake, C., Chambers, B., Cheung, A., \& Davis, S. (in press). Effective reading programs for the elementary grades. Review of Educational Research. http://www.edweek.org.

Spector, M., Merrill, M. D., Merrienboer, J. V., \& Driscoll, M. (2008) Handbook of research on educational communications and technology, Third Edition. New York: Routledge.

van den Akker, J., \& Kuiper, W. (2008). Research on models for instructional design. In M. J. Spector, D. M. Merrill, J. van Merrienboer \& M. P. Driscoll (Eds.), Handbook of research and educational communications and technology (3rd ed., pp. 739-748). New York, NY: Taylor \& Francis Group.

Videro, D. (2009). New head of U.S. research agency aims for relevance. Education Week, 29(13), 10.

Correspondence: Steven M. Ross, Professor, Center for Research and Reform in Education, Johns Hopkins University, 2800 North Charles Street, Baltimore, MD 21218, United States. 